\title{
The enhancing effects of a chicken-meat extract on serum Ig concentrations in normal and scalded animals
}

\author{
Yan Chun Man ${ }^{1}$, Chung Wai Yee ${ }^{1}$, Wong Kwok Shing ${ }^{2}$, Tang Pak Lai ${ }^{1}$, Wan Koon Ching ${ }^{1}$ and Ko Kam Kei ${ }^{1}$ \\ ${ }^{1}$ School of Nursing, The Hong Kong Polytechnic University, Hunghom, Kowloon, Hong Kong \\ ${ }^{2}$ Faculty of Health and Social Sciences, The Hong Kong Polytechnic University, Hunghom, Kowloon, Hong Kong
}

(Received 6 October 2004 - Revised 27 January 2005 - Accepted 1 February 2005)

\begin{abstract}
The aim of the study was to investigate the effects of a chicken-meat extract known as Essence of Chicken (EOC) on immune function in a normal and scalded animal model. In this experimental study, 120 rats were randomly allocated into three groups: a SHAM group (inflicted with a sham wound), a BURN group (inflicted with a full-thickness scald wound covering $30 \%$ of total body surface area) and a CONTROL group. Rats in the SHAM and BURN groups were further divided into normal saline (NS)-fed and EOC-fed groups. They were fed by force-feeding with a feeding needle and blood samples were taken from each group on days 1, 8, 15 and 22 postburn. Serum IgG, IgA and IgM concentrations were determined by ELISA and the results of the EOC-fed and NS-fed cohorts of both the SHAM and BURN groups were compared. The level of significance was set at $P<0 \cdot 05$. Serum IgG level of both SHAM-EOC and BURN-EOC cohorts showed significant elevation on day 8. IgA exhibited a significant increase in the SHAM-EOC group on day 15 and in the BURN-EOC group on day 22. A significant increase of IgM level was found on days 1 and 22 for the SHAM-EOC group and on day 15 for the BURN-EOC group. Conclusively, EOC was shown to have an enhancing effect on serum Ig levels for both normal and tissue-stressed rats. It is suggested that EOC may help improve immune function when the immune system is at normal status or when it faces a challenge.
\end{abstract}

Chicken-meat extract: Burn: Ig: Immunosuppression

A chicken-meat extract known as Essence of Chicken (EOC) is regarded as a nutritious food supplement in Chinese communities. Since 1989, the health efficacy and benefits of EOC have been confirmed through a series of scientific research studies. The beneficial effects include accelerating the restoration of serum Fe to normal levels after blood donation by regular blood donors (Williams \& Schey, 1993) and stimulating Hb restoration in Fe-deficient rats by enhancing the bioavailability of food $\mathrm{Fe}$ (Geissler et al. 1996). Other benefits include promoting recovery from mental fatigue in man by enhancing the metabolism of stress-related substances in blood (Nagai et al. 1996) and improving the recovery status of anxious subjects during psychotherapy (Azhar et al. 2001). EOC has also been shown to have an antihypertensive effect in a rat model that may be useful as a prophylactic treatment for hypertension and related tissue injury (Matsumura et al. 2001, 2002). Moreover, EOC has been shown to exert anticardiac hypertrophic and anti-arteriosclerotic actions (Sim, 2001).

Ig are antibodies belonging to a group of glycoproteins that are secreted by B lymphocytes. When invading antigens are encountered, B lymphocytes proliferate and large amounts of antibody are manufactured. Ig play an important role in humoral immune responses by recognizing foreign antigens and provoking immune cascades. Several studies have noted that levels of $\mathrm{IgG}$, $\operatorname{IgA}$ and $\operatorname{IgM}$ in serum drop following profound tissue injuries, including injuries presented in human and animal burn models
(Arturson et al. 1969; Munster et al. 1970; Bjornson et al. 1976; Sengupta et al. 1980; Winkeltein, 1984; Bariar et al. 1994). Such depression in Ig levels can impair the immune capabilities of patients, thus compromising the ability to resist postburn infections and further increasing morbidity and mortality (Warden \& Ninnemann, 1981). Studies have demonstrated that changes in the hormonal environment postburn create conditions prone to increased proteolysis and nitrogen loss (Rolandelli et al. 1998; Saffle \& Hildreth, 2002). Therefore, in the event of injury, it is suggested that adequate quantities of protein and amino acids must be supplied in order to satisfy ongoing metabolic demands and provide amino acids for protein synthesis. Supporting the production of proteins such as Ig is expected to promote immunocompetence and hence recovery following severe burn injury (Peck \& Chang, 1999; Saffle \& Hildreth, 2002).

It is well documented that EOC is abundant in proteins extracted from chicken meat (Matsumura et al. 2002), which may provide a dietary source for protein after severe thermal injury. Candlish (1998) also demonstrated that EOC contains high- and low-molecular-weight factors (the low one is possibly carnosine) that can activate human circulating neutrophils. These studies support the proposed role for EOC in enhancing the synthesis and activation of immune system components.

The present study investigated the enhancing effects of EOC on serum IgG, IgA and IgM concentrations in a normal and scaldburned rat model. In previous studies, the reduction of serum 
$\operatorname{IgG}, \operatorname{Ig} \mathrm{A}$ and $\operatorname{IgM}$ initiated on day 1 postburn and reached a trough at about days 3-5 (Arturson et al. 1969; Munster et al. 1970; Bjornson et al. 1976; Sengupta et al. 1980; Winkeltein, 1984; Bariar et al. 1994). IgG has usually shown a more profound depression than IgA and IgM (Kohn \& Cort, 1969; Hansbrough et al. 1987). Depending on the type of Ig, the levels returned to normal gradually at different times within 1-2 months.

\section{Materials and methods}

\section{Study design}

A three-group experimental design was used. An animal model of burn injury was employed for the study. One hundred and twenty rats were allocated randomly into three groups as shown in Fig. 1:

(1) SHAM (experimental group) without challenge. The rats were not inflicted with a scald wound. They were further divided into two subgroups. One group was fed $0.9 \%$ normal saline (NS; $n$ 24) while the other group was fed EOC ( $n$ 24). NS served as the placebo.

(2) BURN (experimental group) with challenge. The rats were inflicted with scald wound. They were divided further into two subgroups and received either NS ( $n$ 24) or EOC ( $n$ 24). NS was used as a placebo.

(3) CONTROL. The rats received no treatment throughout the experiment (n 24).

All rats in the BURN group were scalded to induce an externally inflicted wound. A full-thickness scald burn with $30 \%$ total body surface area was inflicted on the rats at the beginning of the experiment (day 0). All the rats in the SHAM group received a fake scald wound. The rats in the SHAM group and the BURN group were fed with $0.9 \%$ NS (NS group) or fresh undiluted EOC (EOC group) for twenty-two consecutive days. Blood samples were taken from all groups on days 1, 8, 15 and 22 for analysis.

\section{Animal experiments}

One hundred and twenty male Sprague-Dawley rats with an average body weight of 200-220 g (6 weeks old) were obtained from the animal laboratory of a local university. They were housed in a separate room and caged individually. Room temperature was maintained between 18 and $22^{\circ} \mathrm{C}$ and the humidity was kept at $60-70 \%$. The rats were maintained in an artificial $12 \mathrm{~h}$ light (07.00-19.00 hours) $-12 \mathrm{~h}$ dark cycle. They were allowed free access to standard commercial rodent chow and water. Prior to the experiment, they were kept in a separate room for 1 week to adapt to the environment and for quarantine.

All procedures were approved by Department of Health, The Hong Kong Government and the Animal Subjects Ethics Subcommittee, The Hong Kong Polytechnic University.

\section{Materials}

The NS used was commercially available $0.9 \%$ normal saline (B. Braun Medical Industries, Penang, Malaysia). The bottled EOC (70 ml/bottle; Cerebos (Pacific) Limited, Singapore) was manufactured in Thailand. The rats were fed $0.76 \mathrm{ml} \mathrm{NS}$ or EOC $/ \mathrm{kg}$ body weight according to their grouping. The EOC fed to the rats daily was undiluted and drawn from freshly opened bottles.

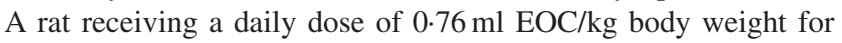
$22 \mathrm{~d}$ is approximately equivalent to a $70 \mathrm{~kg}$ man consuming half a bottle $(70 \mathrm{ml})$ of EOC per day (Xu \& Sim, 1997). The solutions were administered directly into the oesophagus by use of a feeding needle.

\section{Scald infliction and blood sampling}

Each rat in the BURN group was inflicted with a scald wound according to the protocol of Walker \& Mason (1968). The area to be scalded was calculated. The rat was anaesthetized with sodium pentobarbital $(50 \mathrm{mg} / \mathrm{kg}$ body weight, intraperitoneally; Abbott Laboratories, Chicago, IL, USA). The dorsum hair on the area to be scalded was shaved. The rat was fixed in the specially designed 'burning device' and only the skin to be scalded was exposed. The exposed skin was immersed in water at $95^{\circ} \mathrm{C}$ for $10 \mathrm{~s}$ to produce a third-degree full-thickness scald wound. On removal from water, the scalded area was dried by rolling the rat quickly on a sterilized towel, to avoid further burn. The rats were resuscitated with $0.9 \%$ NS $(20 \mathrm{ml} / \mathrm{kg}$ body weight, subcutaneously). Finally they were released and caged. A hot lamp was used to reduce heat loss until the anaesthetic wore off.

A fake scald wound was applied to the rats in the SHAM group. The procedure for infliction of the fake scald was similar to that used on the BURN group rats, except that the exposed skin was immersed in water at $22^{\circ} \mathrm{C}$ instead of $95^{\circ} \mathrm{C}$. Buprenorphine $(0.05 \mathrm{mg} / \mathrm{kg}$ body weight, subcutaneously; Reckitt Benckiser Healthcare (UK) Limited, Hull, UK) was given to the BURN group rats daily as an analgesic; the SHAM group rats also received the analgesic to avoid possible differences caused by drug actions.

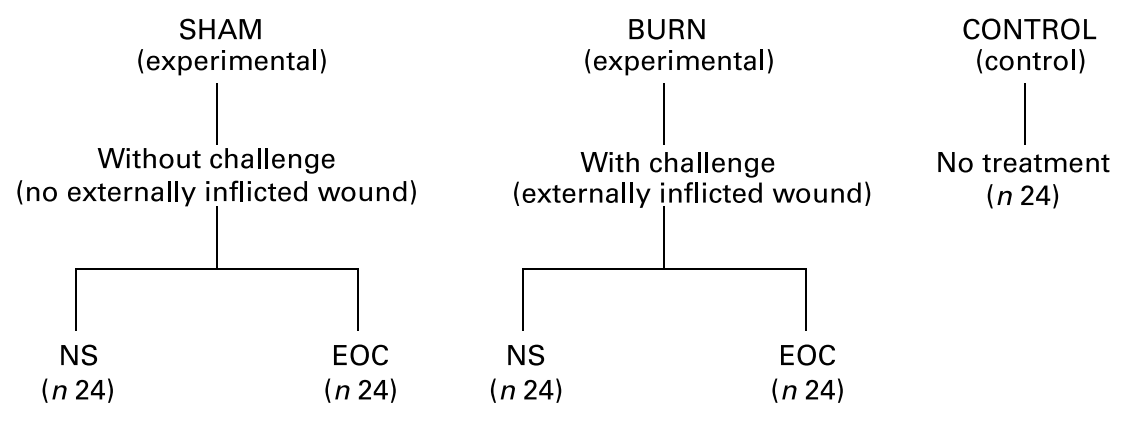

Fig. 1. Diagrammatic illustration of the study design. NS, normal saline; EOC, Essence of Chicken (chicken-meat extract). 
Blood samples were obtained by cardiac puncture under anaesthesia on days $1,8,15$ and 22 . The rats were then killed. The collected blood samples were allowed to clot in a plastic tube at room temperature for $1 \mathrm{~h}$. Clotted blood was centrifuged at $3000 \mathrm{rpm}$ for $10 \mathrm{~min}$. The serum samples obtained were transferred to micro-tubes and stored at $-30^{\circ} \mathrm{C}$ until analysis.

\section{ELISA for serum total IgG, IgA and IgM}

The serum total $\mathrm{IgG}, \operatorname{IgA}$ and $\operatorname{IgM}$ concentrations were measured by sandwich ELISA. The tests were based on commercially available assay kits designed specifically for rat total $\operatorname{IgG}, \operatorname{IgA}$ and IgM (Bethyl Laboratories Inc., Montgomery, TX, USA). The sensitivity of the kits was $7.8-500 \mathrm{ng} / \mathrm{ml}$ for total $\mathrm{IgG}, 15.625-$ $1000 \mathrm{ng} / \mathrm{ml}$ for $\operatorname{IgA}$ and $31.25-2000 \mathrm{ng} / \mathrm{ml}$ for $\mathrm{IgM}$; there was no cross-reactivity with other Ig. In brief, the anti-rat capture antibodies were diluted 1000 times with $50 \mathrm{mM}-\mathrm{Na}_{2} \mathrm{CO}_{3}$ solution, $\mathrm{pH}$ 9.6, and each well of a 96-well plate (Greiner Bio-One, Frickenhausen, Germany) was coated with $100 \mu$ l of the antibodies overnight at $4^{\circ} \mathrm{C}$. After incubation, the solution was removed and the plate was washed five times with PBS containing Tween 20 (PBS-Tween 20). Then blocking solution $(200 \mu \mathrm{l})$ was added to each well and incubated at $37^{\circ} \mathrm{C}$ for $30 \mathrm{~min}$, the solution was removed and the plate washed five times with PBS-Tween 20. The wells were treated with $100 \mu$ l rat serum $\left(10^{5}\right.$-fold dilution for $\operatorname{IgG}$ and $\operatorname{IgM}, 10^{2}$-fold dilution for $\left.\operatorname{IgA}\right)$ and incubated at $37^{\circ} \mathrm{C}$ for $1 \mathrm{~h}$, and then washed ten times with PBS-Tween 20. Next, $100 \mu \mathrm{l}$ anti-rat antibodies-horseradish peroxide conjugated antibodies was added to each well and incubated at $37^{\circ} \mathrm{C}$ for another hour, followed by washing five times with PBS-Tween 20. The colour-changing substrate solution was freshly prepared by dissolving $70 \mathrm{mg} o$-phenylenediamine dihydrochloride and $20 \mathrm{mg}$ urea-hydrogen peroxide in $100 \mathrm{ml}$ peroxidase substrate buffer (Chui et al. 1989). Then the substrate solution $(100 \mu \mathrm{l})$ was added to each well and incubated for $30 \mathrm{~min}$ for colour development. Finally, $50 \mu \mathrm{l} 4 \mathrm{M}-\mathrm{H}_{2} \mathrm{SO}_{4}$ was added to each well to stop the reaction and the colour was measured using micro-titre plate reader at $450 \mathrm{~nm}$. All chemicals were purchased from Sigma-Aldrich (St. Louis, MO, USA) unless mentioned otherwise.

\section{Statistical analysis}

Data are presented as means with their standard errors. ANOVA was used to detect significant differences between Ig levels of the NS and EOC groups. The level of significance was set at $P<0 \cdot 05$.

\section{Results}

All animals survived the study period. None of them died as a result of infection.

The serum Ig levels in all groups during the experimental period are shown in Table 1 . No statistically significant difference was noted in serum $\operatorname{IgG}, \operatorname{Ig}$ A and $\operatorname{IgM}$ concentrations between the CONTROL and SHAM-NS groups. Therefore, the intake of NS in the SHAM group did not initiate any effect on serum Ig concentrations. Concerning the effect of burn injury on serum Ig concentrations, a significantly low serum $\mathrm{IgG}$ concentration was found in the BURN-NS group on days 1 and 8 postburn (both $P<0.05 v$. SHAM-NS). A similar result was also obtained for serum $\operatorname{Ig}$ A concentration on days 1 and $8(P=0.02$ and $P=0.01$ respectively $v$. SHAM-NS). The only significant drop in serum IgM concentration in the BURN-NS group was noted on day 8 postburn ( $P=0.02 v$. SHAM-NS).

Serum Ig levels were promoted following consumption of EOC, in both SHAM and BURN groups. A significant elevation of serum $\operatorname{IgG}$ level in the EOC group was noticed on day 8 for the SHAM group $(P=0.01$ v. SHAM-NS group $)$; a similar result was also found for the BURN group on day 8 postburn $(P=0.02 v$. BURN-NS group). A significant difference in serum

Table 1. The effect of chicken-meat extract (Essence of Chicken; EOC) and normal saline (NS) on serum IgG, IgA and IgM concentrations in experimental groups (SHAM, inflicted with a sham wound; BURN, inflicted with a full-thickness scald wound covering $30 \%$ of total body surface area) on days $1,8,15$ and 22 . CONTROL shows the normal level for each Ig in serum (Mean values with their standard errors for six rats in each group for an individual day)

\begin{tabular}{|c|c|c|c|c|c|c|c|c|c|c|}
\hline & & & \multicolumn{4}{|c|}{ SHAM } & \multicolumn{4}{|c|}{ BURN } \\
\hline & \multicolumn{2}{|c|}{ CONTROL } & \multicolumn{2}{|c|}{ NS } & \multicolumn{2}{|c|}{ EOC } & \multicolumn{2}{|c|}{ NS } & \multicolumn{2}{|c|}{ EOC } \\
\hline & Mean & SEM & Mean & SEM & Mean & SEM & Mean & SEM & Mean & SEM \\
\hline \multicolumn{11}{|c|}{$\lg G(\mathrm{mg} / \mathrm{ml})$} \\
\hline Day 1 & 0.960 & 0.045 & 0.917 & 0.022 & 0.919 & 0.043 & 0.747 & 0.010 & 0.676 & 0.030 \\
\hline Day 8 & 0.951 & 0.042 & 0.959 & 0.047 & $1 \cdot 118^{*}$ & 0.039 & 0.673 & 0.030 & $0.832^{*}$ & 0.048 \\
\hline Day 15 & 0.934 & 0.052 & 1.061 & 0.059 & $1 \cdot 104$ & 0.048 & $1 \cdot 170$ & 0.069 & $1 \cdot 117$ & 0.073 \\
\hline Day 22 & 0.930 & 0.055 & 1.034 & 0.026 & $1 \cdot 104$ & 0.038 & 1.071 & 0.042 & $1 \cdot 122$ & 0.030 \\
\hline \multicolumn{11}{|c|}{$\lg \mathrm{A}(\mathrm{mg} / \mathrm{ml})$} \\
\hline Day 1 & 0.078 & 0.003 & 0.079 & 0.002 & 0.085 & 0.003 & 0.068 & 0.002 & 0.060 & 0.004 \\
\hline Day 8 & 0.079 & 0.005 & 0.079 & 0.004 & 0.078 & 0.003 & 0.064 & 0.003 & 0.070 & 0.003 \\
\hline Day 15 & 0.079 & 0.001 & 0.078 & 0.002 & $0.098^{*}$ & 0.002 & 0.073 & 0.001 & 0.069 & 0.001 \\
\hline Day 22 & 0.079 & 0.005 & 0.076 & 0.001 & 0.072 & 0.002 & 0.066 & 0.001 & $0.078^{\star}$ & 0.003 \\
\hline \multicolumn{11}{|c|}{$\operatorname{lgM}(\mathrm{mg} / \mathrm{ml})$} \\
\hline Day 1 & 0.846 & 0.058 & 0.770 & 0.029 & $0.989^{*}$ & 0.022 & 0.710 & 0.017 & 0.654 & 0.065 \\
\hline Day 8 & 0.730 & 0.054 & 0.851 & 0.050 & 0.941 & 0.045 & 0.685 & 0.018 & 0.800 & 0.038 \\
\hline Day 15 & 0.838 & 0.067 & 0.928 & 0.028 & 1.002 & 0.014 & 0.887 & 0.033 & $1.097^{\star}$ & 0.099 \\
\hline Day 22 & 0.845 & 0.068 & 0.953 & 0.065 & $1.389^{*}$ & 0.126 & 0.874 & 0.044 & $1.081 \dagger$ & 0.045 \\
\hline
\end{tabular}

Mean value in the EOC group was significantly higher than that in the corresponding NS group: ${ }^{*} P<0.05$.

†Cases with marginal insignificance. 
IgA between the EOC and NS groups was found in the SHAM group on day $15(P<0.05 v$. SHAM-NS $)$ and in the BURN group on day $22(P=0.03 v$. BURN-NS). The serum IgM level in the SHAM-EOC group was significantly higher than in the SHAM-NS group on day 1 and day $22(P=0.01$ and $P<0.05$ respectively). In the BURN group, the serum IgM level of the EOC group was significantly higher than that of the NS group on day $15(P=0 \cdot 04)$.

There was a marginal case of the BURN-EOC group showing a greater level of IgM on day $22(P=0.07 v$. BURN-NS) that did not reach statistical significance.

\section{Discussion}

For the BURN groups, serum $\operatorname{IgG}, \operatorname{IgA}$ and $\operatorname{IgM}$ concentrations decreased immediately after the burn wound had been inflicted. This suggests that the traumatic injury impaired the immune functions of the animals and caused immunosuppression. The consumption of EOC had no significant effect on the serum IgG, $\operatorname{IgA}$ and $\operatorname{IgM}$ concentrations on the 1st day after burn infliction, as their levels stayed close to those in their respective NS group (placebo group). Also, for the SHAM groups, EOC did not show any effect on serum IgG and IgA levels on day 1 . However, there was a significant increase in IgM levels. EOC seems to elevate the serum IgM level in normal rats immediately after consumption.

Interestingly, most of the EOC effects on serum Ig levels commenced on or after the 8th day postburn. Significant elevations were noticed in all Ig levels in both the SHAM and the BURN groups. This delay in serum Ig-promoting action is possibly due to the time needed for digestion and assimilation of the meat proteins and dipeptides from the EOC into the components of the immune system.

A significant increase in serum $\operatorname{IgA}$ level was found in the SHAM group on day 15 and in the BURN group on day 22 . EOC had a relatively less significant effect on serum IgA levels throughout the experiment. This lesser effect on IgA could result from its presence mainly in the mucous membranes and it might be released into the circulating system only in small amounts. Therefore, changes in serum IgA levels caused by traumatic injury and consumption of EOC were insignificant and difficult to detect.

It seems that, compared with controls, EOC consumption is capable of increasing serum Ig concentrations in burned rats postburn. Although Ig levels are restored naturally after burn injury, the recovery period may be extensive and in a prolonged immunosuppressive state the incidence of post-injury morbidity and mortality may increase. Hence, a faster recovery of Ig levels after thermal injury has clinical significance. It may help to reduce susceptibility to bacterial and viral infections in patients with tissue injuries, such as surgery and trauma patients; and in turn reduce morbidity and mortality. The increased Ig levels in normal rats reflect that EOC consumption promotes the immune functions of the body to meet any immunological challenge encountered in daily life. However, as the body needs time to assimilate the meat proteins, EOC should be consumed longterm to allow the immune-enhancing effects to commence immediately.

As previously above, EOC may contain some proteins that have beneficial effects on immunological responses. Sim (2002) reported that the nutrients possessing these actions include amino acids (arginine, glutamine and glycine), fatty acids such as $n-3$ PUFA and antioxidants such as vitamins $\mathrm{C}$ and $\mathrm{E}$. Minehira et al. (2000) also found that immune function could be moderated by the selection and combination of dietary protein. The presence of proteins, vitamins and nutrients in EOC, along with the known rich content of the active dipeptides carnosine and anserine (Candlish, 1998), support its potential in enhancing immune function. However, further investigation is needed to understand the mechanism by which EOC enhances immune functions; and what other components in the immune system, such as $\mathrm{T}$ and $\mathrm{B}$ lymphocytes, IL and CD (cluster designation) systems, may be affected by EOC consumption.

Other studies have also revealed that diets containing specific protein supplements possess immune-enhancing effects. Choudhry et al. (2003) reported that the supplement of an immune-enhancing diet which contained arginine, glutamine, fish oil and dietary nucleotides to burned rats can prevent the burn-related suppression of mesenteric lymph node $\mathrm{T}$ cell proliferation and IL-2 production. The supplement of arginine was also demonstrated to enhance $\mathrm{T}$ cell function and reduce the immunosuppression induced by surgical trauma (Daly et al. 1988, 1990). Meanwhile, glutamine is an oxidative fuel for rapidly replicating immune cells, including gastrointestinal mucosal cells, lymphocytes and macrophages (Biffl et al. 2002). However, the effects of these dietary proteins on Ig are still unknown.

According to previous studies, immune functions were affected most severely on days $3-5$ postburn. The Ig levels on these days were not determined in the present study because we aimed to investigate overall trends in serum Ig changes after the intake of EOC for a long period. Moreover, the alterations of Ig concentrations in the early stage postburn may be composition effects resulting from stress due to experimental treatments, and not EOC alone. A $7 \mathrm{~d}$ sampling interval was set to study any change in Ig levels that arose solely from EOC. However, further study may be needed to investigate early immunological responses in order to complete the picture. It is also unclear whether this effect would be observed in human subjects. Again, these queries have to be supplemented by further studies.

In conclusion, the present study has demonstrated that EOC can enhance the serum Ig levels of both normal and tissue-stressed rats. As EOC is a safe and readily available health food supplement, it is suggested that EOC is a good choice for people who have just experienced tissue stress, including pregnancy, surgery or injury, to boost immune functions and speed of the response, and hence reduce the occurrence of post-injury infections.

\section{Acknowledgements}

The study was kindly sponsored by Cerebos (Pacific) Limited and supported by The School of Nursing, The Hong Kong Polytechnic University.

\section{References}

Arturson G, Hogman CF, Johansson SGO \& Killander J (1969) Changes in immunoglobulin levels in severely burned patients. Lancet 293, $546-548$

Azhar MZ, Abdul Razak K \& Mohsin SSJ (2001) The use of chicken essence as an adjunct to psychotherapy in anxious subjects - a clinical assessment. Malaysia J Psychiatry 9, 13-22. 
Bariar LM, Bal A, Hasan A \& Sharma V (1994) Serum levels of immunoglobulins in thermal burns. J Indian Med Assoc 94, 133-134.

Biffl WL, Moore EE \& Haenel JB (2002) Nutrition support of the trauma patient. Nutrition 18, 960-965.

Bjornson AB, Altemeier WA \& Bjornson HS (1976) Changes in humoral components of host defense following burn trauma. Ann Surg 186, 88-96.

Candlish JKA (1998) A traditional blood remedy as a modulator of the respiratory burst of the human neutrophil: an in vitro study. Int $J$ Food Sci Nutr 49, 55-63.

Choudhry MA, Haque F, Khan M, Fazal N, Al-Ghoul W, Ravindranath T, Gamelli RL \& Sayeed MM (2003) Enteral nutritional supplementation prevents mesenteric lymph node T-cell suppression in burn injury. Crit Care Med 31, 1764-1770.

Chui SH, Wan KC, Lam CWK \& Lewis WHP (1989) Enzyme-linked immunosorbent assay for free thyroxin in human serum. Clin Chem 35, 1770-1772.

Daly JM, Reynolds J, Sigal RK, Shou J \& Liberman MD (1990) Effect of dietary protein and amino acids on immune function. Crit Care Med $\mathbf{1 8}$ Suppl. 2, S86-S93.

Daly JM, Reynolds J, Thom A, Kinsley L, Dietrick-Gallagher M, Shou J \& Ruggieri B (1988) Immune and metabolic effects of arginine in the surgical patient. Ann Surg 208, 512-523.

Geissler C, Boroumand-Naini M, Harada M, Iino T, Hirai K, Suwa Y, Tanaka $\mathrm{T}$ \& Iwata S (1996) Chicken extract stimulates haemoglobin restoration in iron deficient rats. Int J Food Sci Nutr 47, $351-360$.

Hansbrough JF, Zapata-Sirvent RL \& Peterson VM (1987) Immunomodulation following burn injury. Surg Clin North Am 67, 69-92.

Kohn J \& Cort DF (1969) Immunoglobulins in burned patients. Lancet 293, 836-837.

Matsumura Y, Kita S, Ono H, Kiso Y \& Tanaka T (2002) Preventive effect of a chicken extract on the development of hypertension in stroke-prone spontaneously hypertensive rats. Biosci Biotechnol Biochem 66, 1108-1110.

Matsumura Y, Okui T, Ono H, Kiso Y \& Tanaka T (2001) Antihypertensive effects of chicken extract against deoxycorticosterone acetate-saltinduced hypertension in rats. Biol Pharm Bull 24, 1181-1184.
Minehira K, Inoue S, Nonaka M, Osada K, Yamada K \& Sugano M (2000) Effects of dietary protein type on oxidized cholesterolinduced alternation in age-related modulation of lipid metabolism and indices of immune function in rats. Biochim Biophys Acta 1483, $141-153$.

Munster AM, Hoagland HC \& Pruitt BA (1970) The effect of thermal injury on serum immunoglobulins. Ann Surg 172, 965-969.

Nagai H, Harada M, Nakagawa M, Tanaka T, Gunadi B, Setiabudi ML, Uktolseja JL \& Miyata Y (1996) Effects of chicken extract on the recovery from fatigue caused by mental workload. Appl Human Sci 15, 281-286.

Peck MD \& Chang Y (1999) Nutritional support for burn injuries. J Nutr Biochem 10, 380-396.

Rolandelli RH, Koruda MJ, Fukuchi SG, Rombeau JL \& Stein TP (1998) The effect of glutamine- and alanine-enriched total parenteral nutrition on postburn proteolysis in the rat. J Nutr Biochem 9, 28-30.

Saffle JR \& Hildreth M (2002) Metabolic support of the burned patient. In Total Burn Care, pp. 271-287 [D Herndon, editor]. London: Harcourt Publishers Limited.

Sengupta SR, Sukhtankar AY, Dhole TN \& Dubey KP (1980) Humoral immunity in burns. Burns 172, 172-175.

Sim KM (2002) Management of severe burns injuries - a metabolic perspective. Curr Anaesth Crit Care 13, 76-82.

Sim MK (2001) Cardiovascular actions of chicken-meat extract in normoand hypertensive rats. Br J Nutr 86, 97-103.

Walker HL \& Mason AD (1968) A standard animal burn. J Trauma 8, 1049-1051.

Warden GD \& Ninnemann JL (1981) The immune consequences of thermal injury: an overview. In The Immune Consequences of Thermal Injury, pp. 1-20 [JL Ninnemann, editor]. Baltimore, MD: The Williams and Wilkins Company.

Williams AT \& Schey SA (1993) Use of a traditional blood remedy: a study on regular blood donors. Int J Food Sci Nutr 44, 17-20.

Winkeltein A (1984) What are the immunological alterations induced by burn injury? J Trauma 24, 572-573.

Xu CL \& Sim MK (1997) Effect of oral feeding of essence of chicken on the level of 5-hydroxyindole acetic acid in the cerebrospinal fluid of the rat. Int J Food Sci Nutr 48, 113-117. 